УДК 101.1:316

DOI: 10.18101/1994-0866-2019-2-74-82

\title{
ПРОБЛЕМА ОТЧУЖДЕНИЯ ЧЕЛОВЕКА В РОССИЙСКОМ ОБЩЕСТВЕ И ГЛОБАЛЬНОМ МИРЕ
}

\author{
(c) Евлоева Фатима Рашидовна \\ кандидат философских наук, доцент, \\ Ингушский государственный университет \\ Россия, 366700, г. Магас, пр-т Зязикова, 7 \\ E-mail: evloeva.lm@mail.ru
}

В данной статье дается понятие отчуждения человека от человека, общества и государства; указываются формы, в которых оно проявляется. Рассматриваются главные причины отчуждения в российском обществе: глубокое имущественное неравенство и социальная несправедливость; несовершенство правоохранительной системы; алчность, социальная безответственность и компрадорский характер среднего и крупного бизнеса; отсутствие полноценного и систематического диалога между властными структурами и гражданским обществом при принятии решений, затрагивающих жизненные интересы широких слоев населения. В статье также указаны возможные способы снижения уровня отчуждения в России: реформа системы правопорядка; формирование социально ответственного бизнеса; стимулирование активности гражданского общества; выравнивание глубоких имущественных и социальных различий между гражданами; ориентация государства и гражданского общества на ценности реального гуманизма.

Проблема отчуждения в настоящей статье рассматривается и в глобальном аспекте как следствие капиталистической системы воспроизводства. Ее проявления - нищета, голодная смерть, болезни, антисанитарные условия жизни больших масс людей, ютящихся в гетто, количество и численность обитателей которых в разных странах, в том числе развитых, неуклонно увеличивается. Настало время озаботиться данной проблемой международным организациям, общественным движениям, прогрессивным политическим партиям, людям доброй воли, которым небезразличны судьбы сотен миллионов несправедливо обездоленных людей.

Ключевые слова: отчуждение; социальная справедливость; гражданское общество; государство; бизнес; СМИ; классы; социальные группы; глобализация мирового сообщества; социальное неравенство; правовой нигилизм; мировой капитализм.

Для цитирования:

Евлоева Ф. Р. Проблема отчуждения человека в российском обществе и глобальном мире // Вестник Бурятского государственного университета. Философия. 2019. Вып. 2. C. $74-82$.

Многие явления сегодняшней жизни вызывают тревогу за будущее человечества и непосредственно российского общества. Это происходящие в различных странах частые нарушения политической стабильности, включая локальные войны, уносящие жизни сотен тысяч молодых, здоровых, полных надежд на лучшее будущее людей (только за последние годы они произошли в Ираке, Ливии, продолжаются в Сирии, на Украине); небывалая ранее активность международных террористических групп; финансовые и экономические кризисы, резко снижающие уровень жизни широких кругов населения; стихийные бедствия; весьма да- 
лекие от целесообразных и гармоничных отношения между властью и интеллектуальной элитой, властью и народом в нашей и других странах.

В России ситуация осложняется значительной криминализацией государственных структур и бизнеса, с которой российская власть борется, но недостаточно активно.

В сравнении с недалеким советским прошлым нашего общества резко снизился его интеллектуальный и духовный потенциал; наблюдается целенаправленное выхолащивание гуманистического содержания духовной культуры. Прагматизм и утилитаризм, неотъемлемые от капиталистического производства и потребления, в настоящее время пронизывают «...все сферы общественной жизни - управление, науку, образование, здравоохранение, сферу общения между людьми, досуг и даже семейные отношения» [6, с. 8].

Корысть, выгода, приобретательство, материальная сторона жизни, деньги стали доминирующими ценностями в обществе, что неизбежно сопровождается девальвацией духовных и нравственных ценностей: эрудиции, образованности, компетентности, милосердия, доброты, душевной щедрости, открытости, взаимопомощи, сострадания и др.

Современные средства массовой информации - печать, радио, кинематограф, телевидение и особенно интернет - много способствуют дегуманизации и деинтеллектуализации общества, широко пропагандируя, в первую очередь среди молодежи, бездуховные и даже безнравственные образ жизни, вкусы, потребности в угоду правящим и влиятельным экономическим, политическим, финансовым структурам, извлекающим огромные прибыли из такого рода деятельности СМИ.

Указанные явления вызывают глубокое отчуждение человека от человека, от семьи, общества и государства. Не случайно в мире за последние десятилетия в семейно-брачных отношениях существенно повысился показатель разводов, понизился процент желающих вступить в зарегистрированный брак и предпочитающих брак гражданский. Рождаемость во многих развитых странах Европы уменьшилась до критического уровня, грозящего демографической катастрофой.

Отчуждение как социальное явление характеризует не только современное общество. Оно имеет историческое происхождение и возникло в связи с расколом общества на классы. Классовая борьба между рабами и рабовладельцами, феодалами и крепостными крестьянами, капиталистами и наемными рабочими происходила и происходит на разных этапах истории общества после его вступления в эпоху цивилизации. На современном этапе оно приобрело небывалые масштабы и угрожающий характер в связи с глобализацией мирового сообщества и накоплением беспрецедентных по своей мощи средств массового уничтожения.

Философская мысль на современном этапе, отражая важнейшие формы отчуждения, существующие в обществе, акцентирует внимание на тех из них, в которых человек ощущает себя лишенным своих важнейших сущностных характеристик. Это проявляется и в чувстве бессилия, связанного с неподконтрольностью его жизни и судьбы его воле, их подчиненностью внешним силам и обстоятельствам; и в ощущении бессмысленности существования, ибо зачастую невозможно для рядового человека добиться с помощью рационально организованных действий желаемого результата; и в осознании разрушения традиционной системы ценностей, для которой были важными взаимные обязательства людей по соблюдению общепринятых социальных и моральных норм; и в ощущении оди- 
ночества, исключенности из системы социальных связей, в том числе семейных, дружеских, соседских, родственных; и в ощущении утраты человеком своего подлинного «я», своей индивидуальности (самоотчуждение).

Социальная база отчуждения и конфликтности в российском обществе достаточно широка. В первую очередь это различные виды социального неравенства, доминирующим среди которых является имущественное неравенство, а также коррумпированная правоохранительная система и недостаточный уровень развития гражданского общества.

«Резкое и все усиливающееся расслоение населения страны на значительную группу малообеспеченных (около 65\%), малочисленную группу обеспеченных (14\%) и среднеобеспеченных (21\%), по данным социологических исследований... приводит к социальной поляризации общества и не способствует его интеграции, гармонии и толерантности» [3, с. 49].

Соответственно, снижение уровня конфликтности и достижение национального согласия требуют принятии целого ряда мер, в первую очередь нивелирования глубоких социально-экономических различий между классами, другими социальными группами.

Не менее актуальна для России задача реализации принципа действительного равенства всех граждан перед законом. В этой области нам многое еще предстоит сделать. Произвол и беззаконие в системе государственного управления и в судебной деятельности - исконная беда России. К этому следует добавить произвол в сфере бизнеса — новообретение российского общества последних десятилетий.

Интеллигенция, будучи образованной, мыслящей частью общества, так и не смогла внедрить в его сознание представление о первостепенной значимости права в общественной жизни, ничем не уступающего по своей культурной ценности религии, морали, искусству, науке. Правоохранительная система в России не осозналав полной мере свою ответственность за неукоснительное соблюдение в обществе норм, защищающих достоинство, права и свободы каждого индивида, независимо от его имущественного положения, социального статуса, принадлежности к властным структурам и т. д.

В Конституции Российской Федерации и других нормативных правовых актах достоинство, права и свободы человека и гражданина защищены законодательно, однако на практике они либо не реализуются вовсе, либо реализуются не в полной мере. Широкие массы людей не обладают достаточной правовой культурой, не знают свои права и способы их защиты, в силу чего люди нередко становятся жертвами всякого рода мошенников, аферистов, недобросовестных работников правоохранительных структур, работодателей, которые в свою корысть обращают их правовую некомпетентность.

К тому же законодательство России очень сложно для понимания человека, не являющегося специалистом в этой области, часто противоречивое, что дает возможность работникам судебных органов различно толковать те или иные нормы. По этой причине многим правонарушителям и преступникам удается избежать ответственности, в особенности если они являются бизнесменами, влиятельными чиновниками и просто владельцами крупной собственности. Подобные явления широко распространены в нашей действительности, что усиливает атмосферу недоверия и отчуждения между гражданским обществом и государ- 
ством. Здесь необходима широкая и систематическая просветительская работа компетентных структур, направленная на повышение правовой грамотности населения.

Гражданское общество в России все еще не стало действенной силой, активно участвующей в обсуждении и решении важнейших общественных вопросов. Несмотря на предпринимаемые государством усилия по мобилизации широких масс людей для реализации амбициозных проектов в социально-экономической, технологической, демографической, культурной сферах и обеспечения модернизационного прорыва России, гражданское общество еще не включило в себя основную массу населения, не преодолело недоверие к государству, ощущает себя отчужденным от него, главным образом из-за вопиющего имущественного неравенства между различными социальными группами, а также правового нигилизма.

О недостаточности обратной связи населения с властью в нашей стране свидетельствует, к примеру, ограниченный круг лиц, допущенных к обсуждению решений, затрагивающих жизненные интересы широких слоев населения, таких как проведенные ранее пенсионная реформа, реформа ЖКХ, реформа в системе образования, переименование милиции в полицию и др. Отметим как положительный пример, что ожидающаяся пенсионная реформа широко обсуждается на разных уровнях, включая СМИ, политические круги общества, государственные структуры, общественные организации, встречи депутатов со своими избирателями и т. д.

Властные структуры в российском обществе в должной мере не взаимодействуют и с интеллектуальной элитой общества по вопросам, связанным с жизнью и трудовой деятельностью населения страны, изучением природы социального неравенства, историей и последствиями приватизации в России, причинами криминализации общества, произволом новоиспеченной российской буржуазии. Эти вопросы в высшей степени важные для всякого человека, который хочет знать общество, в котором он живет, быть уверенным в том, что оно справедливое и гуманное, ощущать себя полезным и значимым для него, иметь равные со всеми права и обязанности.

«Самый страшный удар по общественному единству проистекает обычно не от разнообразия идей и подходов в решении тех или иных проблем, а от искусственно создаваемой невозможности одной части общества систематически подключаться к достигнутому уровню общенациональной культуры как в духовном, так и в экономическом плане... Проблема общественного единства напрямую упирается в относительную равномерность доступности системных сфер жизнедеятельности (здравоохранение, образование, наука, окружающая среда (экономика, политика, искусство, сфера услуг и т. д. -. . $E$.)), имеющих общественное значение и непосредственно общественную природу» [2].

Серьезной помехой на пути преодоления отчуждения человека труда, народа от государства в России является произвол, царящий в сфере крупного бизнеса и его компрадорский характер, выражающийся в вывозе получаемых в России доходов и активов за рубеж вместо их использования для развития экономики России. Также не способствует консенсусу в обществе глубокая криминализация российского бизнеса, проявляющаяся в нелегальных, попросту незаконных способах приобретения, владения и использования капиталов, включая чрезмерную, 
неконтролируемую государством эксплуатацию труда наемных работников, значительно, более чем в два раза, превышающую норму прибыли российских капиталистов в сравнении с нормой прибыли в развитых странах Запада. Теневой бизнес и его безнаказанный уход от уплаты налогов - также обычное, широко распространенное явление в России.

Неуемная алчность российского бизнеса вызвана наряду с прочим корыстью и коррумпированностью топ-чиновников, принимающих угодные бизнесменам административно-управленческие решения в обмен на «откаты», размер которых, по оценкам экспертов, составляет от четверти до половины прибыли многих собственников. «Последние в силу той же мотивации компенсируют подобные "расходы", ограничивая долю заработной платы наемных рабочих в добавленной стоимости 30-35\%, в то время как цивилизованная норма развитых стран составляет 60-65\%... Столь же произвольно собственники минимизируют затраты на модернизацию оборудования и улучшение условий труда, что ведет к отказу от инноваций, к стагнации производительности труда, стагнации производства, повышению аварийности, травматизму и т. д.» [4].

Изменить эту ситуацию можно и необходимо для гармонизации общественных отношений, преодоления глубокого отчуждения между трудящимися массами и бизнесом, нона то требуются воля государства и активная, бескомпромиссная позиция общественных организаций и гражданского общества в целом, а также российской политической и интеллектуальной элиты, понимающей огромный вред для российской экономики компрадорского и социально безответственного вектора ее развития и не препятствующей этому явлению.

Отчуждение между государством, бизнесом и широкими народными массами питается, как упоминалось выше, огромным имущественным неравенством между различными классами и социальными группами, которое имеет место быть в нашем обществе. Люди не понимают, почему одни категории работников имеют доходы в размере сотен и более миллионов рублей в год, а другие - две-три сотни тысяч рублей за такой же период. Разве труд учителя, врача, инженера, строителя, агрария менее важен и нужен обществу, чем труд парламентария, крупного государственного чиновника, бизнесмена, топ-менеджера или у последних другая природа, сверхчеловеческая?

Каждый здравомыслящий человек понимает, что труд может быть различной степени сложности, требующим значительного объема знаний, опыта, квалификации, сопряженным с опасностями для жизни и здоровья, и что такой труд должен оплачиваться высоко. И все же разность в оплате труда не должна быть столь разительной, какой она является в современном российском обществе. Та система распределения производимых в нашей стране материальных и духовных благ вызывает недоумение и недовольство, расценивается как вопиющая социальная несправедливость.

Социальная справедливость - величайшая ценность, без реализации которой общество не может быть устойчивым, консолидированным, поступательно развивающимся, инновационным. При ее отсутствии ущемленные и обделенные массы людей утрачивают мотивацию к труду, трудовая деятельность и ее результаты отчуждаются от человека, труд превращается в тяжелую обязанность - он не приносит удовлетворения, не способствует развитию человека как личности, сковывает его инициативу и творчество. 
Для русского человека, россиянина социальная справедливость традиционно была приоритетной ценностью. Идея «свободного, справедливого и коллективистского (солидарного) общественного строя глубоко укоренена в культуре русского народа, всех народов России. Справедливость выступает стержневой, объединяющей темой во всех духовных исканиях русского человека. Русская культура всегда критически относилась к рыночной выгоде, к индивидуализму, к культу денег и прагматической морали» [7].

Принятие российским государством решительных, действенных мер для сокращения резких различий в уровнях доходов различных категорий граждан, окончательного преодоления бедности, а также пропаганда ценности и значимости всякого общественно полезного труда, формирование атмосферы уважения и почитания человека труда и жесткого порицания всякого рода мошенников, аферистов, коррупционеров в высшей степени актуально для нашего общества.

В жесточайшей конкурентной борьбе, которая происходит в современном мире, Россия может оказаться аутсайдером, если не будут найдены и реализованы способы достижения согласия между различными социальными группами внутри страны, в первую очередь между трудящимися, бизнесом и государством. Необходима переориентация нашего общества в пользу поддерживаемого большинством населения варианта социума с демократическим политическим режимом, действенным гражданским обществом, социально ответственным бизнесом. «Пришло время общероссийского дискурса, использующего методологию критического гуманизма и нацеленного на достижение национального консенсуса относительно вектора гуманистической модернизации России, на преодоление практик вседозволенного этатизма и укоренение практик реального гуманизма» [5].

Социальная несправедливость, проявляющаяся в голоде, крайней нищете, бесправии, отсутствии доступа к самым необходимым материальным и духовным благам сотен миллионов людей, проживающих на нашей планете, - явление глобального масштаба. А. А. Бирюков пишет: «...несмотря на все усилия, прилагаемые международным сообществом, около 1,5 миллиарда людей на нашей планете по-прежнему живут в условиях многомерной бедности. По оценкам Организации по питанию и сельскому хозяйству OOH (FAO) сегодня в мире насчитывается почти 870 миллионов людей, страдающих от недоедания. Это оставляет 12,5\% населения планеты (каждый восьмой человек). Ежегодно от голода умирают 30 миллионов человек, из которых 6 миллионов - дети. По данным Всемирной организации здравоохранения,783 миллиона человек не имеют доступа к чистой питьевой воде... Все большее количество людей в мире, переселяющихся из сельской местности в города, оказываются запертыми в кольце пригородных трущоб, где они вынуждены существовать в условиях жуткой антисанитарии, отсутствия водопровода, канализации и прочих элементов инфраструктуры любого нормального города. Численность обитателей этих гетто в мире неуклонно растет, составляя уже более 900 миллионов человек» [1].

Описанная ситуация имеет место быть в мире, в котором накоплены колоссальные материальные и духовные богатства, которых не знало ни одно из предшествующих обществ в человеческой истории. Справедливое и рациональное их распределение позволило бы обеспечить нормальные, достойные условия жизни для всех людей, живущих на Земле. Невольно напрашивается вывод, что 
такая ситуация не может быть случайной, неотвратимой, естественной. Она есть порождение всей системы современного глобального капитализма с его беспредельной алчностью, стяжательством, равнодушием к бедам незаслуженно обездоленных людей.

О ненасытной, хищнической природе мирового капитализма свидетельствуют нижеприведенные цифры: «На начало XXI в. богатство трех человек превышало доход 48 наименее развитых стран с населением 600 миллионов жителей... Если жители стран центра, которые составляют 20\% населения планеты, потребляют 86\% всех материальных благ, создаваемых в мире, то 20\% землян, проживающих в наименее развитых обществах, довольствуется 1,3\%. К концу 20 -го столетия глобальное неравенство достигло невероятного для коэффициента Джинни уровня $0,67 »[1]$.

Эти цифры убедительно показывают, что тенденция к абсолютному обнищанию подавляющего большинства жителей нашей планеты есть объективная и закономерная тенденция функционирования и развития современного мирового капитализма.

Для системы капиталистического воспроизводства безработные, нищие, обездоленные люди являются лишними с экономической и социальной точек зрения. От них данная система стремится всячески отгородиться. Ей требуются лишь сильные, здоровые, успешные, конкурентоспособные люди, использование которых сулит капиталистам дальнейшее обогащение.

Стремление изолироваться от «лишних людей» выражается в первую очередь в равнодушии богатых и успешных к их судьбам, в высокомерном презрении к ним как к неудачникам, в раздражении по поводу того, что они являются как бы немым укором их богатой и респектабельной жизни.

Особенно зримо, выпукло, можно сказать, беззастенчиво, это наблюдается в нашей стране, в которой народившаяся всего несколько десятилетий назад буржуазия, ставшая за этот короткий срок баснословно богатой (по-видимому, государство мало интересует вопрос, какими путями и способами это богатство было нажито), беззастенчиво эксплуатирует наемных работников и не обременяет себя благотворительной деятельностью в пользу малоимущих, безработных, больных сограждан.

Глубокое отчуждение между богатыми и бедными в нашей стране и за рубежом проявляется и в обустройстве пространства крупных населенных пунктов, при котором максимально уменьшается возможность пересечения между ними. «Визуальным воплощением данной стратегии сегодня является распространение во всех мировых мегаполисах "архитектуры страха", включающей в себя строительство блокпостов, контрольно-пропускных пунктов, домов-крепостей, окруженных высокими стенами, увенчанными колючей проволокой, возведение железных ворот и заборов, находящихся под электрическим напряжением, и т. д. По одну сторону этих стен находятся обособленные, закрытые элитные зоны, защищенные от всех посторонних высокими ограждениями и частными охранными армиями. По другую - разрастающиеся мировые трущобы, превратившиеся в свалку избыточного человечества. Вопрос состоит в том, долго ли смогут эти стены сдерживать отчаяние и боль людей, которые сами себя лишними не считают» [1]. 
Удручающая по своей безнравственности и несправедливости картина. В разумном обществе, которому не чужды морально-нравственные нормы, таких явлений не должно быть. Поскольку они есть, более того, широко распространены, это свидетельствует о глубоко аномальном состоянии капиталистического общества как доминирующего общественного строя в современном мире. Человечество должно, обязано и в силах изменить данную ситуацию, создать такую систему производства и распределения материальных и духовных благ в мировом масштабе, которая обеспечила бы безбедное и достойное существование всем людям на Земле.

Это вполне реализуемая задача при наличии доброй воли и согласия в этом вопросе небезразличных групп людей, включая различные общественные движения и организации, левые политические партии и их сторонников, международные гуманитарные организации, демократические государственные структуры внутри национальных государств и в международном масштабе.

\section{Лuтература}

1. Бирюков А. А. Избыточное человечество? Мальтузианство и марксизм о проблеме «лишних людей» [Электронный ресурс] // Вопросы философии. 2015. № 12. URL: http://vphil.ru/index.php?option=com_content\&task=view\&id=1313 (дата обращения: 20.09.2018).

2. Глинчикова А. Г. Частная собственность и общественный интерес - дилемма России [Электронный ресурс] // Вопросы философии. 2011. № 3. C. 3-11. URL: http://vphil.ru/index.php?option=com_content\&task=view\&id=284 (дата обращения: 20.09.2018).

3. Голенкова 3. Т. Основные тенденции изменения социальной структуры российского общества в условиях глобализации и трансформации [Электронный ресурс] // Философия науки. 2011. № 4. C. 44-58. URL: http://www.academyrh.info/html/2011/fn-4.pdf (дата обращения: 20.09.2018).

4. Лапин Н. И. Фундаментальные ценности цивилизационного выбора в XXI столетии. Ч. 1. Человеческая цивилизация перед выбором конфигурации фундаментальных ценностей [Электронный ресурс] // Вопросы философии. 2015. № 6. URL: http://vphil.ru/index.php?option=com_content\&task=view\&id=1137\&Itemid=52 (дата обращения: 20.09.2018).

5. Лапин Н. И. Фундаментальные ценности цивилизационного выбора в XXI столетии. Ч. 2. Аксиологические предпосылки цивилизационного выбора России [Электронный ресурс] // Вопросы философии. 2015. № 6. URL: http://vphil.ru/index.php?option=com_content\&task=view\&id=1176 (дата обращения: 20.09.2018).

6. Сиземская И. Н. Исторический выбор: от демократии к охлократии // Философия науки. 2011. № 5. С. 5-8.

7. Шевченко В. Н. Национальный путь развития России в контексте нового этапа модернизации страны [Электронный ресурс] // Национальная идея России: материалы всеpoc. науч. конф. (Москва, 12 ноября 2010 г.). С. 151-165. URL: https://books.google.ru/books?id=2dE2hRX7Z9sC\&pg=PA164 (дата обращения: 20.09.2018). 


\section{PROBLEM OF HUMAN ALIENATION FROM THE RUSSIAN SOCIETY} AND THE GLOBAL WORLD

Fatima R. Evloyeva

Cand. Sci. (Philos.), Ingush State University,

7 Zyazikova Prospect, Magas 386001, Russia

E-mail: evloeva.lm@mail.ru

The article deals with the concept of the alienation of human from human, society, and the state, its forms and manifestations. We have considered the main causes of alienation in the Russian society, such as deep property inequality and social injustice; imperfection of the law enforcement system; greed, social irresponsibility and comprador nature of medium and large businesses; absence of a full-fledged and systematic dialogue between the authorities and civil society in making decisions that affect the vital interests of the broad population. The article also proposes the possible ways to reduce the level of alienation in Russia: reformation of the rule of law system; development of sustainable business; stimulation of the activity of civil society; alignment of profound property and social differences between citizens; orientation of the state and civil society on the values of real humanism.

The problem of alienation is also considered in the global aspect as a consequence of the capitalist reproduction system, its manifestations are poverty, starvation, diseases, unsanitary living conditions of large masses of people, increase in the number of inhabitants of ghettos in different countries, including developed ones. Today, international organizations, public movements, progressive political parties, and people of good will who care about the fate of hundreds of millions of unfairly disadvantaged people should bother with this problem.

Keywords: alienation; social fairness; civil society; the state; business; mass media; social classes; social groups; globalization of the world community; social inequality; legal nihilism; world capitalism. 